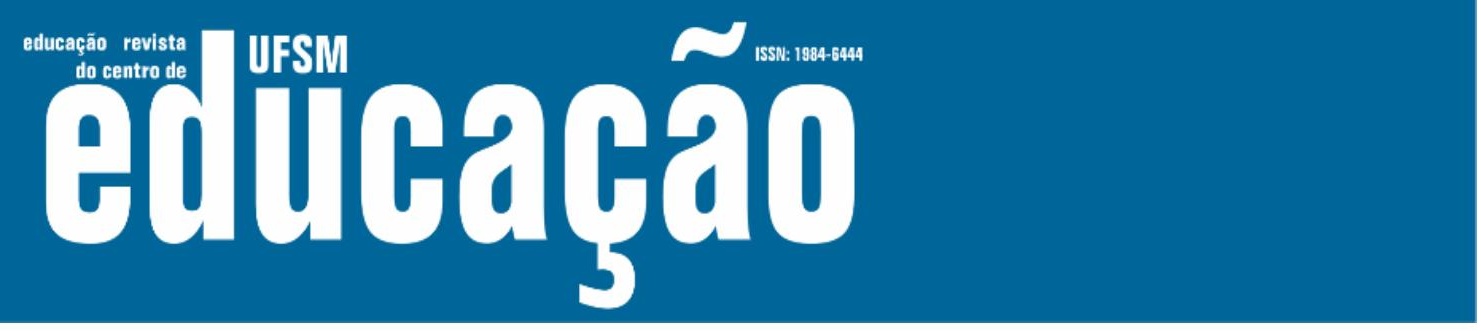

ISSN: 1984-6444 | http://dx.doi.org/10.5902/1984644440682

\title{
Memória Educativa como dispositivo de pesquisa: tecendo laços na Universidade
}

\author{
Educational Memory as a research device: weaving ties at the University
}

Cleonice Pereira do Nascimento Bittencourt

Doutoranda na Universidade de Brasília. Brasília, Distrito Federal, Brasil.

cleonascimentoead@gmail.com - https://orcid.org/0000-0001-8265-2106

Inês Maria Marques Zanforlin Pires de Almeida

Professora doutora na Universidade de Brasília. Brasília, Distrito Federal, Brasil.

almeida@unb.br - https://orcid.org/0000-0002-1292-7327

Claudia Marcia Lyra Pato

Professora doutora na Universidade de Brasília. Brasília, Distrito Federal, Brasil.

claudiap@unb.br - https://orcid.org/0000-0003-0324-2075

Katilen Machado Vicente Squarisi

Doutoranda na Universidade de Brasília. Brasília, Distrito Federal, Brasil.

Katilensquarisi@gmail.com - http://orcid.org/0000-0002-7461-2718

Recebido em 19 de outubro de 2019

Aprovado em 24 de agosto de 2020

Publicado em 31 de janeiro de 2021

\section{RESUMO}

O objetivo deste trabalho é apresentar a memória educativa como um dispositivo de pesquisa, fundamentado no aporte teórico da psicanálise, articulado com a educação. Para tanto, fez-se o levantamento das produções acadêmicas do Programa de PósGraduação em Educação da Universidade de Brasília, no período de 2007 a 2019, disponíveis no repositório da instituição. Foram utilizados os descritores memória educativa, psicanálise e educação, que resultaram na identificação de 23 dissertações de mestrado e 2 teses de doutorado. Todas usaram a memória educativa sob o enfoque psicanalítico com a educação. As análises qualitativas foram organizadas em eixos e categorias temáticas. Os resultados indicaram que o uso do dispositivo, em que os sujeitos escrevem suas memórias, associadas ao contexto pedagógico e de formação, favoreceu a reflexão não só dos sujeitos das pesquisas como também dos próprios pesquisadores. A escrita sobre as experiências escolares, a relação com os professores, o contexto sociocultural associado a essa trajetória revelou diferentes dimensões na atuação pessoal e profissional. Refletir sobre a própria trajetória escolar e de formação contribuiu para melhor compreensão do processo reflexivo e constitutivo da subjetividade docente. Com base no olhar psicanalítico foi possível 


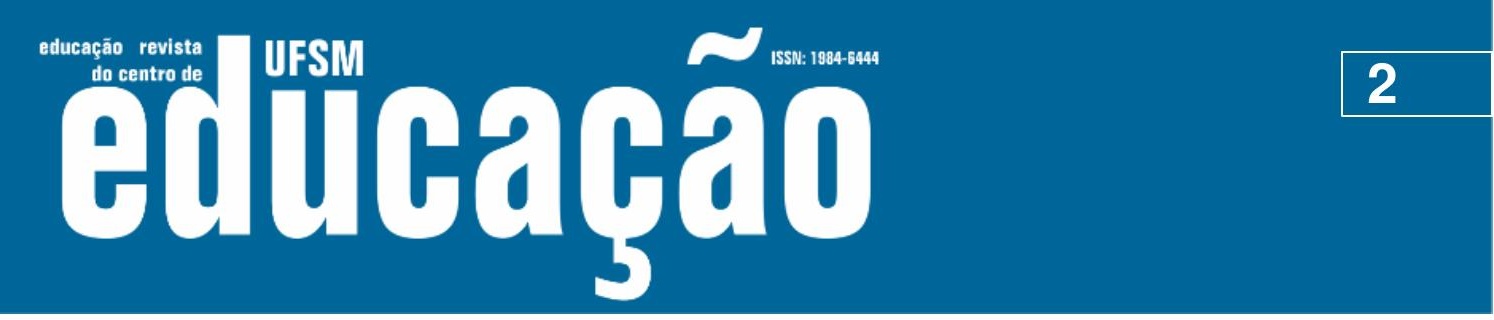

ISSN: 1984-6444 | http://dx.doi.org/10.5902/1984644440682

inferir que a escrita da memória educativa fez emergir uma compreensão sobre a própria atuação docente, com possíveis repercussões na subjetividade dos sujeitos. Esses achados apontam para a contribuição desse dispositivo de pesquisa no campo da educação, em especial para os estudos sobre a formação do professor.

Palavras-chave: Memória educativa; Psicanálise e educação; Formação de professores.

\section{ABSTRACT}

This paper aims to present the educational memory as a research device, based on the theoretical contribution of psychoanalysis, articulated with education. For that, we searched academic productions of the Graduate Program in Education of the University of Brasilia, from 2007 to 2019, were made available in the institution's repository. The keywords educational memory, psychoanalysis, and education were used, which resulted in the identification of 23 master's degree dissertations and 2 doctoral theses. All used educational memory under the psychoanalytical approach with education. Qualitative analyzes were organized into axes and thematic categories. The results indicated that the use of the device, in which the subjects write their memories associated with the educational and training context, promoted the reflection not only of the research subjects but also of the researchers themselves. Writing about school experiences, the relationship with teachers, the socio-cultural context associated with this trajectory revealed different dimensions in personal and professional performance. Reflecting on their own school and educational trajectory contributed to better understanding the reflective and constitutive process of teaching subjectivity. Based on the psychoanalytic view, it was possible to infer that the writing of the educational memory brought to light an understanding of the teaching performance itself, with possible repercussions on the subjectivity of the subjects. These findings point to the contribution of this research device to the field of education, especially for studies on teacher education.

Keywords: Educational memory; Psychoanalysis and education; Teacher training.

\section{Introdução}

Apesar do contexto atual enfrentado pelas universidades brasileiras, com expressivas transformações, em especial, no que tange ao apoio para o desenvolvimento de pesquisas no âmbito da pós-graduação, observa-se um movimento crescente das produções acadêmicas dessas instituições de ensino, pesquisa e extensão, com inegáveis repercussões em rankings nacionais e 


\section{Uism

ISSN: 1984-6444 | http://dx.doi.org/10.5902/1984644440682

situações são resgatadas na memória. Esse movimento de retorno, possibilita ao sujeito sistematizar criticamente suas representações e seus sentimentos, a partir de sua experiência como aluno, em relações educativas pessoais e/ou profissionais como docente. A figura abaixo ilustra o processo metodológico de construção da memória educativa.

Figura 1 - Processo metodológico de construção da Memória Educativa

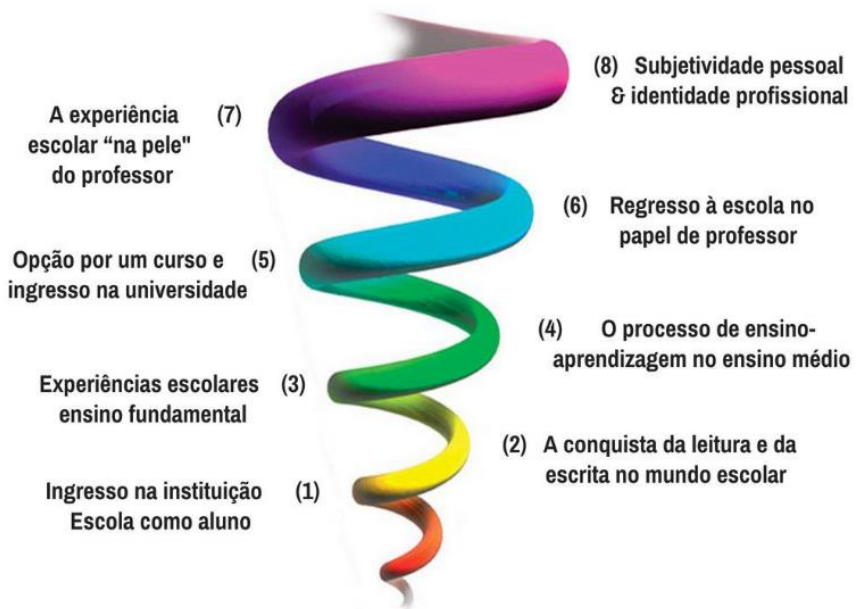

Fonte: Inspirado no Módulo Comum. Imersão no Processo Educativo das Ciências e da Matemática. Programa de Aperfeiçoamento de Professores de Ensino Médio (Pró-Ciências 1997- 1998), Universidade Aberta do Distrito Federal -UNAB, Brasília, Brasil.

Para ativar essas memórias, os pesquisadores oferecem um roteiro orientador ao sujeito pesquisado, que é baseado na estrutura apresentada na figura 1, acima. Assim, facilita o registro de seu percurso desde as primeiras experiências de infância em contexto escolar até a universidade. Para aqueles que já atuam como professores, o dispositivo permite ir além, visitando e redimensionando o vivido, ao trazer à tona também suas experiências como docentes. Neste papel, possibilita dizer das relações com seus pares, dos conteúdos, das metodologias, das atividades e avaliações utilizadas, bem como da família, da sociedade e da dimensão político-social vivenciada, podendo acrescentar, inclusive, momentos que the trouxeram prazer ou desprazer. Ao final desse processo, o sujeito pesquisado é solicitado a se posicionar sobre a escolha da profissão, considerando sua trajetória como aluno e como 


\section{تilloapẫ}

ISSN: 1984-6444 | http://dx.doi.org/10.5902/1984644440682

professor.

No processo de escrita da memória educativa é possível utilizar imagens, desenhos, fotos e filmes, sem delimitação de números de páginas, a critério do sujeito de pesquisa. Se necessário, o pesquisador pode sugerir, inclusive, o uso de outros dispositivos ou técnicas de pesquisa que permitam aprofundar esse processo de resgate da memória associada às questões educacionais, conforme o objeto da pesquisa. Entende-se que "tanto a psicanálise como a educação não podem parar de rever seus métodos em função de seus objetivos, e não rever seus objetivos em função de seus métodos" (KUPFER et.al, 2010, p.294).

A seguir, apresenta-se o levantamento das produções acadêmicas em educação, que utilizaram a memória educativa como um dispositivo de pesquisa, a fim de ilustrar e apontar as contribuições desse dispositivo para a ressignificação da atuação docente.

\section{O uso do dispositivo Memória Educativa em pesquisas de educação sob enfoque psicanalítico - uma meta-análise}

O levantamento das produções acadêmicas que utilizaram o dispositivo da memória educativa foi feito no repositório da Universidade de Brasília e compreendeu o período de 2007 a 2019. Para tanto, foram utilizados os descritores memória educativa, psicanálise e educação, que resultaram na identificação de 23 dissertações de mestrado e 2 teses de doutorado. Todas usaram a memória educativa sob o enfoque psicanalítico com a educação e foram produzidas no âmbito da Faculdade de Educação.

Os temas abordados por esses estudos foram gestão escolar, cenário pedagógico, ação pedagógica, prática pedagógica, inclusão escolar, docência, formação do pedagogo, identidade docente, ambiente virtual de aprendizagem, profissão docente, educação para o trânsito, relações professor-aluno, entre outros. No total, esses estudos tiveram a participação de 264 sujeitos, que elaboraram, individualmente, as suas memórias educativas, seguindo o mesmo roteiro padrão. 


\section{F WEM

ISSN: 1984-6444 | http://dx.doi.org/10.5902/1984644440682

As análises destas 264 memórias educativas foram organizadas em três eixos temáticos: Eixo 1 - Implicações na formação do profissional docente; Eixo 2 Subjetividade e identidade na prática pedagógica; e Eixo 3 - Transferência, afeto e mal-estar no cenário pedagógico. A análise refinada desses eixos fez emergir categorias conceituais que permitiram compreender como os processos subjetivos se desvelam na escrita da memória educativa. As principais categorias encontradas, correspondentes a cada eixo, estão apresentadas no quadro a seguir:

Quadro 1 - Categorias conceituais e respectivo eixo correspondente

\begin{tabular}{|c|c|c|}
\hline Eixo 1 & Eixo 2 & Eixo 3 \\
\hline memória & identidade & transferência \\
\hline inconsciente & subjetividade & afeto \\
\hline identificação & identificação & mal-estar \\
\hline subjetividade & ambivalência & saber \\
\hline estilo de ensino & sedução & poder \\
\hline infantil & desejo & autoridade \\
\hline marcas & & \\
\hline vicissitudes & & \\
\cline { 1 - 3 } & &
\end{tabular}

Fonte: As autoras

Entre essas categorias conceituais pode-se observar que os termos identificação e subjetividade se repetem nos eixos 1 e 2 . Ambos os eixos têm proximidades, uma vez que a formação docente está intimamente conectada à subjetividade e à constituição da identidade do ser professor e do fazer pedagógico. Nessas memórias educativas, foram reveladas experiências e reminiscências das relações dos participantes com seus pais e os seus professores, em um processo de identificação com eles. Para a psicanálise, a identificação é primordial na constituição do sujeito e está presente desde os primeiros momentos de constituição do Ser, sendo destacada ao longo da obra freudiana. Sob esse fundamento, as primeiras experiências se instauram no aparelho psíquico, representadas por traços de memória 


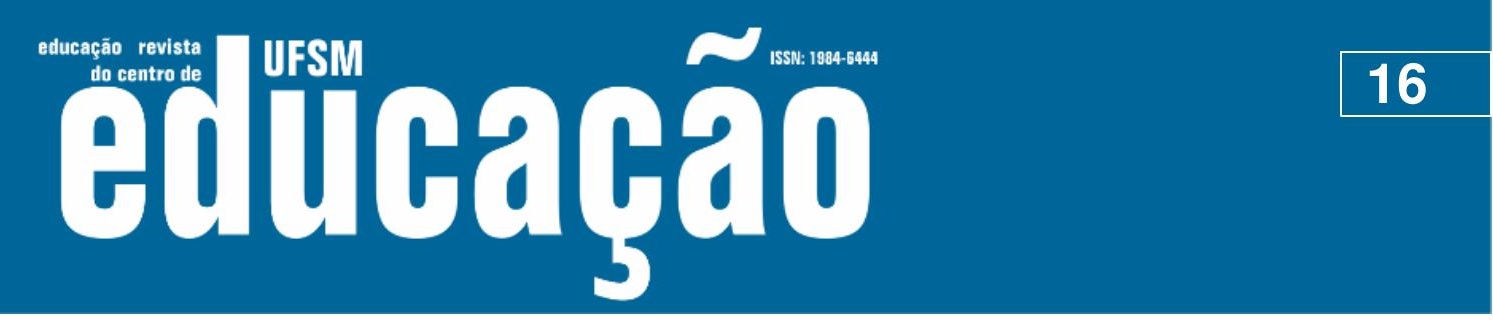

ISSN: 1984-6444 | http://dx.doi.org/10.5902/1984644440682

envolve questões psíquicas internas. Silva (2017) se posiciona diante dos dilemas do eixo formação de professores, reconhecendo que:

\begin{abstract}
aprendi que para os professores apaixonados, isto é, aqueles que são entusiasmados pela arte de formar, formar é: ser um mediador, facilitador ou catalisador. Para eles a relação que se estabelece no processo de formação é mais importante que o conteúdo a ser transmitido, pois formar é levar o aluno a achar seu próprio caminho, a se transformar, a evoluir, a refletir, a se mover, a se relacionar. Processo que se dá internamente tanto por parte do aluno como do professor. É como um jogo lúdico, de muito prazer em que também está se formando, se movimentando, se transformando, evoluindo, se relacionando com trocas ricas e significativas. E, ainda, com disponibilidade para o inesperado, o desconhecido, o que implica o manejo das diferenças, das divergências, presentes em todas as relações humanas (SILVA,2017, p.56).
\end{abstract}

Corroborando com os resultados encontrados no presente estudo, Pereira e Silveira (2015) destacaram 13 eixos temáticos associados às pesquisas produzidas no Brasil, no período entre 1987 e 2012, fundamentadas na relação entre psicanálise e educação. O quadro 2, abaixo, apresenta esses eixos com a respectiva quantidade de trabalhos que os evidenciaram.

Quadro 2 - Eixos temáticos da pesquisa "Análise do Estado da Arte de Psicanálise e Educação no Brasil (1987- 2012)"

\begin{tabular}{|c|c|}
\hline Eixos & Quantidade \\
\hline Subjetividade & 113 \\
\hline Psicanálise e Educação & 92 \\
\hline Infância & 80 \\
\hline Relação professor-aluno & 74 \\
\hline Formação de professores & 65 \\
\hline Aprendizagem & 60 \\
\hline Inclusão & 60 \\
\hline Mal-estar docente & 58 \\
\hline Adolescência & 54 \\
\hline Saúde mental, autismo, & 37 \\
\hline TDAH & 28 \\
\hline Violência & 24 \\
\hline Linguagem & 20 \\
\hline Fracasso escolar & \\
\hline
\end{tabular}

Fonte: As autoras com base nos trabalhos de Pereira e Silveira (2015).

Destacam-se, desse trabalho, os eixos subjetividade, formação de professores e mal-estar docente, para além da pluralidade dos temas. A partir do tema 


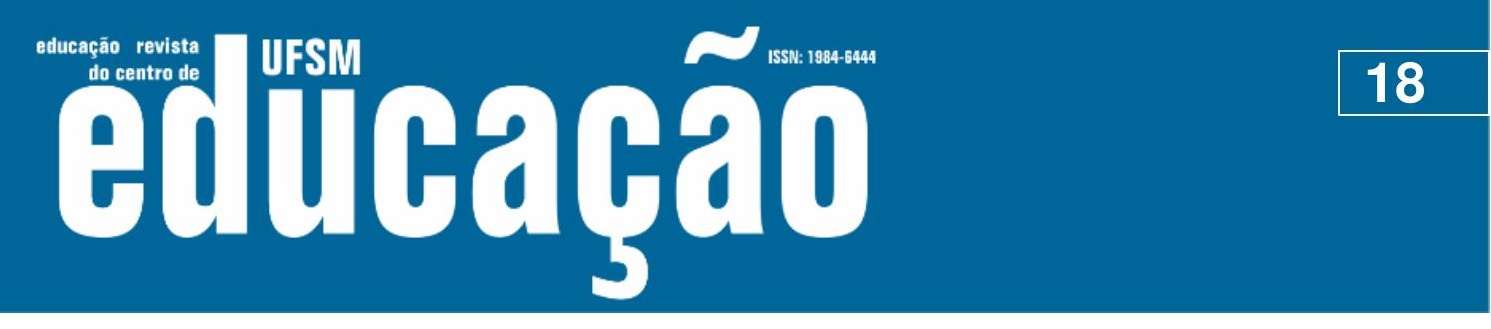

ISSN: 1984-6444 | http://dx.doi.org/10.5902/1984644440682

Quadro 3 - Justificativa dos pesquisadores sobre o uso do dispositivo memória educativa em suas produções

\begin{tabular}{|c|c|c|}
\hline Ano & Autor & justificativa \\
\hline 2007 & PRAZERES & $\begin{array}{l}\text { reconhecer na constituição da identidade do } \\
\text { professor os fatos e as experiências afetivas que } \\
\text { vivenciou como aluno. }\end{array}$ \\
\hline 2008 & CHAUVET & $\begin{array}{l}\text { poderá gerar transformações, } \\
\text { movimentos de de criação, } \\
\text { pessoal/profissional. }\end{array}$ \\
\hline 2008 & BARROSO & $\begin{array}{l}\text { proporcionou escavar e trazer à tona os frutos do } \\
\text { desejo das professoras, possibilitou a reflexão, a } \\
\text { reelaboração e como vimos, possivelmente, a } \\
\text { ressignificação de lembranças e fatos passados } \\
\text { que marcaram, que fizeram sofrer, que causaram } \\
\text { profunda angústia nas professoras pesquisadas, } \\
\text { mas que por meio dessa mesma angústia } \\
\text { pudemos constatar que é possível sair do } \\
\text { sofrimento. }\end{array}$ \\
\hline 2011 & SEGUNDA & $\begin{array}{l}\text { possibilita o regate de vivências, experiências, } \\
\text { sensações sentimentos. }\end{array}$ \\
\hline 2012 & VILA VERDE & $\begin{array}{l}\text { produz efeitos para além daqueles que } \\
\text { pretendemos conscientemente. Refere-se à nossa } \\
\text { própria constituição. É a produção de uma } \\
\text { narrativa endereçada ao Outro e a si mesmo, } \\
\text { dando-nos a possibilidade de vislumbrar uma } \\
\text { aproximação entre trabalho psicanálise e trabalho } \\
\text { pedagógico via elaboração da escrita da Memória } \\
\text { Educativa. }\end{array}$ \\
\hline 2015 & SANTOS & $\begin{array}{l}\text { constitui-se como um dos dispositivos mais } \\
\text { valiosos e estimulantes de pesquisa, lugar de } \\
\text { expressão da subjetividade do percurso } \\
\text { atravessada por pessoas e experiências que } \\
\text { ajudaram na constituição de sua identidade como. } \\
\text { educador, um material do qual, como sujeito } \\
\text { histórico, somente ele possui os registros. }\end{array}$ \\
\hline 2015 & FERREIRA & $\begin{array}{l}\text { como dispositivo de pesquisa tendo em vista que } \\
\text { o efeito que se produz: o tempo da memória vai } \\
\text { atualizando as marcas e dando um novo sentido a } \\
\text { essa história. Resgata-se nesse processo os } \\
\text { vestígios das marcas vividas e ressignificadas na } \\
\text { atualidade. }\end{array}$ \\
\hline 2017 & SQUARISI & $\begin{array}{l}\text { a memória educativa não é simplesmente um texto } \\
\text { documento, mas dispositivo (enunciação mínima } \\
\text { do sujeito inconsciente). }\end{array}$ \\
\hline
\end{tabular}

Fonte: As autoras com base no Repositório Institucional da Universidade de Brasília - Banco de Teses e Dissertações- Faculdade de Educação - PPGE.

É possível depreender desses argumentos que os pesquisadores consideram essencial o uso de uma escuta sensível para se tratar os dados escritos, nesse caso, 


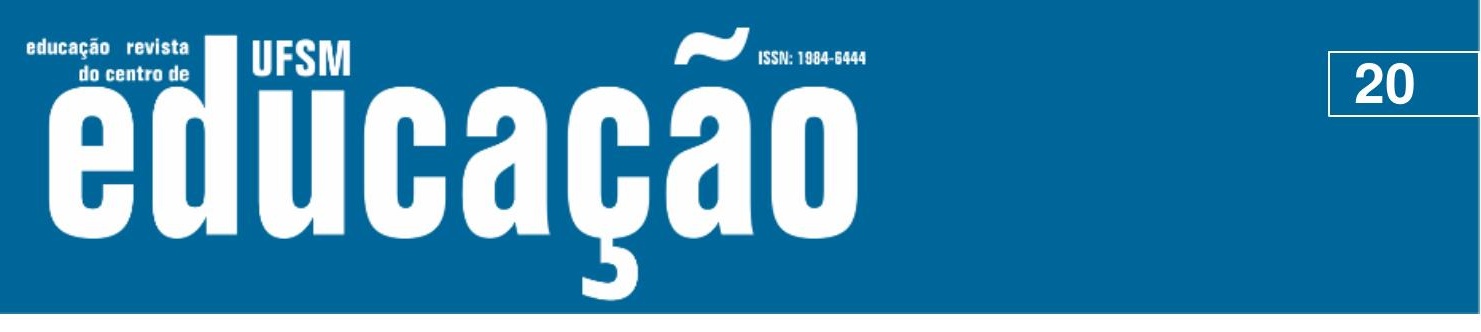

ISSN: 1984-6444 | http://dx.doi.org/10.5902/1984644440682

pesquisas que se originam no campo da articulação entre psicanálise e educação permite inferir que a escrita da memória educativa, nessa perspectiva, pode contribuir de forma original e emblemática para um novo olhar na compreensão da singularidade e na constituição da subjetividade docente. Em alinhamento com os trabalhos de Kupfer et.al (2010) e Pereira e Silveira (2015) para além dos métodos e das técnicas pedagógicas, considera-se que a memória educativa pode facilitar o processo de reconciliação com a criança dentro de cada sujeito envolvido nas pesquisas e resgatar sua capacidade de criar.

\section{Referências}

ALMEIDA, Inês Maria Marques Zanforlin Pires de. Ressignificação do papel da psicologia da educação na formação continuada de professores de ciências e matemática. [Tese de doutorado]. Universidade de Brasília, Brasília, 2001.

ALMEIDA, Inês Maria Marques Zanforlin Pires de. O Ser infante e o Ser professor na memória educativa escolar. In: Colóquio do Lepsi IP/FE-USP, 4., 2002, São Paulo.

Anais eletrônicos. Disponível

em:http://www.proceedings.scielo.br/scielo.php/script=sci_arttext\&pid=MSC0000000 032002000400011\&lng=es\&nrm=abn. Acesso em: 10 Ago. 2020

ALMEIDA, Inês Maria Marques Zanforlin Pires.; BITTENCOURT, Cleonice Pereira do Nascimento. The Writing of Educational Memories as a Significant Research Device. In: ATINERS CONFERENCE PAPER SERIES,23,2018, Athens. 2018, ed. EDU20182496. Athens: Atiner, 2018.Disponível em: https://www.atiner.gr/papers/EDU20182496.pdf. Acesso em: 24 mai. 2019.

BAGNATO, Maria Helena Salgado; COCCO, Maria Inês Monteiro. Memória Educativa e a Tessitura de conceitos educacionais - Experiência Vivenciada na Licenciatura em Enfermagem. Revista Latino-Americana de Enfermagem, [S. I.], v. 10, n.3, p. 247258, 2006. Disponível em: https://www.scielo.br/pdf/rlae/v10n3/13354.pdf Acesso em: 09 de ago.2020

BARROSO, Betania Oliveira. Para além do sofrimento: uma possibilidade de ressignificação do mal-estar docente. [Mestrado em Educação]:Universidade de Brasília, Brasília, 2008.Disponível em: http://repositorio.unb.br/handle/10482/938. Acesso em:05 set.2019.

BIRMAN, Joel. Subjetividade, tempo e psicanálise. Rev. latinoam. psicopatol. fundam., São Paulo, v. 3,n. 4,p. 11-30, Dec. 2000. Disponível em: http://www.scielo.br/scielo.php?script=sci_arttext\&pid=S1415. Acesso em:26 set. 2019. http://dx.doi.org/10.1590/1415-47142000004002. 


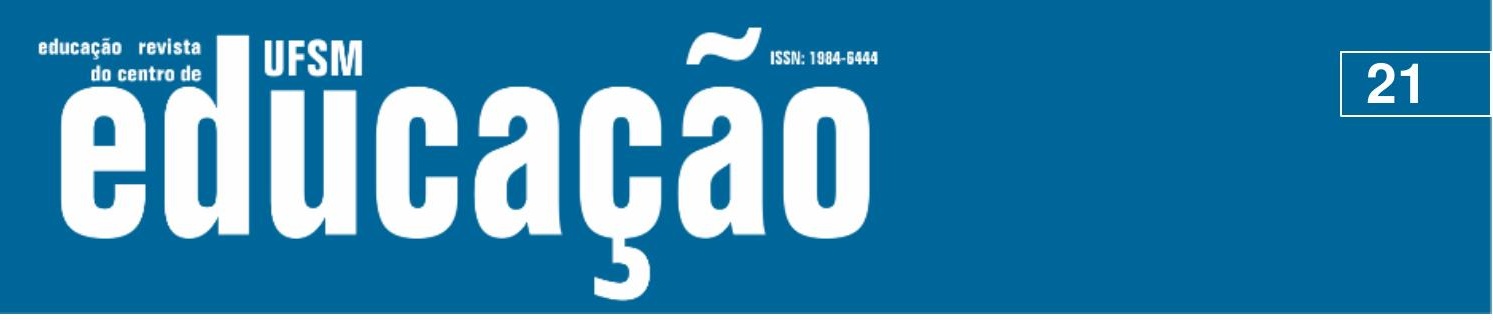

ISSN: 1984-6444 | http://dx.doi.org/10.5902/1984644440682

CHARLOT, Bernard. Da Relação com o Saber Elementos para uma teoria. 1. ed. Porto Alegre: Artmed. 2000.

CHAUVET, Márcia Barra Milhomens. Identidade docente e suas implicações no trabalho pedagógico com adolescentes em situação de risco: uma leitura psicanalítica. [Mestrado em Educação]: Universidade de Brasília, Brasília, 2008.Disponível em: http://repositorio.unb.br/handle/10482/5173.Acesso em:05 set.2019.

FERREIRA, Bárbara Menezes de Medeiros. Educação para o trânsito e o papel dos instrutores: uma leitura psicanalítica. [Mestrado em Educação]: Universidade de Brasília, Brasília, 2015.Disponível em: http://repositorio.unb.br/handle/10482/22681. Acesso em: 05 set.2019.

FOUCAULT, Michel. A escrita de si. In: O que é um autor? Lisboa: Passagens. 1992. p. 129-160.

FOUCAULT, Michel. Poderes e estratégias. In: Coleção Ditos \& Escritos. Rio de Janeiro: Forense Universitária,2003. p.241-252.

FREUD, Sigmund. O Interesse Educacional da Psicanálise. Totem e Tabu e outros trabalhos. In: FREUD, Sigmund. Edição standard brasileira das obras psicológicas completas de Sigmund Freud. Rio de Janeiro: Imago,1996. p.190 -192.

FREUD, Sigmund. Interpretação dos sonhos. In: FREUD, Sigmund. Edição Standard Brasileira das Obras psicológicas completas de Sigmund Freud. Rio de Janeiro: Imago,1996. p.39-79.

FREUD, Sigmund. Uma nota sobre o "Bloco mágico". O Ego e o Id e outros trabalhos.In: FREUD, Sigmund.Edição standard brasileira das obras psicológicas completas de Sigmund Freud. Rio de Janeiro: Imago,1996. p.255-259.

FREUD, Sigmund. Carta 52. In: FREUD, Sigmund. Edição standard brasileira das obras psicológicas completas de Sigmund Freud. Rio de Janeiro: Imago, 1996.

FREUD, Sigmund. Mecanismo Psíquico dos Fenômenos Histéricos. Estudos sobre a histeria. In: FREUD, Sigmund. Edição standard brasileira das obras psicológicas completas de Sigmund Freud. Rio de Janeiro: Imago, 1996. p.39-53

FREUD, Sigmund. Explicações, aplicações e orientações. Novas conferências introdutórias sobre psicanálise e outros trabalhos. In: FREUD, Sigmund. Edição standard brasileira das obras psicológicas completas de Sigmund Freud. Rio de Janeiro: Imago,1996. p. 135-154.

FREUD, Sigmund. Prefácio de A juventude desorientada, de Aichhorn. O Ego e o Id e outros trabalhos. In: FREUD, Sigmund. Edição Standard brasileira das obras psicológicas completas de Sigmund Freud. Rio de Janeiro: Imago.1996. p.307-308. 


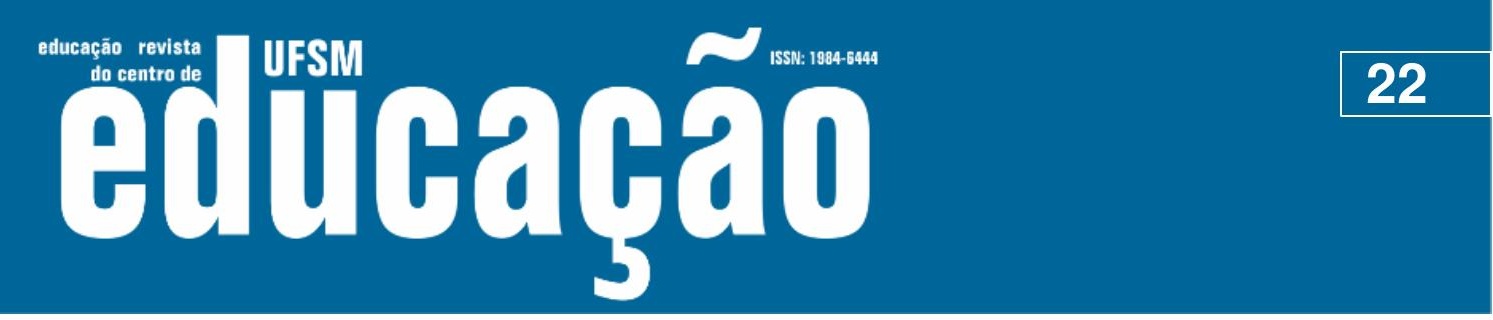

ISSN: 1984-6444 | http://dx.doi.org/10.5902/1984644440682

FREUD, Sigmund. Um estudo autobiográfico. In: FREUD, Sigmund. Edição Standard brasileira das obras psicológicas completas de Sigmund Freud. Rio de Janeiro: Imago, 1996.p 10-74.

FREUD, Sigmund. Charcot. Primeiras Públicações Psicanáliticas. In: FREUD, Sigmund. Edição Standard brasileira das obras psicológicas completas de Sigmund Freud. Rio de Janeiro: Imago, 1996.p. 17- 32.

FREUD, Sigmund. Projeto Para Uma Psicologia Científica. In: FREUD, Sigmund. Edição Standard brasileira das obras psicológicas completas de Sigmund Freud. Rio de Janeiro: Imago, 1996.

KUPFER, Maria. Cristina., COSTA, Beethoven. Hortencio. Rodrigues., De CÉSARIS, Délia. Maaria., CARDOSO, Flávia. Fló., ORNELLAS, Maria. Lourdes., Bastos,

Marise. Bartolozzi., Crochik, Nicole., Palhares, Odana. (2010). A produção brasileira no campo das articulações entre psicanálise e educação a partir de 1980.Estilos da Clínica, 15(2), 284-305. Disponível em:

https://www.revistas.usp.br/estic/article/view/46092.Acesso em: 03 set de 2019.

LAJONQUIÈRE, Leandro de. Figuras do Infantil: a psicanálise na vida cotidiana com as crianças. 1.ed. Petrópolis: Vozes,2010.

MAIA, Gabriela Zambão Abdian. O cotidiano escolar como princípio das pesquisas em educação. Acta Scientiarum. Education, [S. I.], v. 42, p. e47545, 2020. Disponível em: https://doi.org/10.4025/actascieduc.v42i1.47545. Acesso em: 07 de ago. 2020.

MALDANER, Jair José. 0 inconsciente na prática pedagógica. [Mestrado em Educação]:Universidade de Brasília, Brasília, 2009.Disponível em: http://repositorio.unb.br/handle/10482/4062. Acesso em: 05 set.2019.

NOVELI, Márcio; ALBERTIN, Alberto Luiz. Um estudo da virtualização de processos: $\mathrm{O}$ uso de mundos virtuais com foco em ensino-aprendizagem. Revista Brasileira de Educação, [S. I.], v. 22, n. 71, 2017. Disponível em: https://doi.org/10.1590/S141324782017227151. Acesso em:07 de ago. 2020.

NOVOA, Antônio. Formação de Professores e profissão docente. In: NOVOA, Antônio. Os Professores e sua formação. Lisboa: Publicações Dom Quixote, 1992, p.25-30.

OLIVEIRA, Maria Lúcia (Org.). (Im)pertinências da educação: o trabalho educativo em pesquisa. São Paulo: Editora UNESP; São Paulo: Cultura Acadêmica, 2009.Disponível em: http://books.scielo.org/id/vtzmp/pdf/oliveira-9788579830228.pdf. Acesso em: 02 out. 2019.

OLIVEIRA, Rosalina Rodrigues de. A transferência na ação pedagógica: ruído ou música? 2007. [Mestrado em Educação]: Universidade de Brasília, Brasília, 2007. Disponível em: http://repositorio.unb.br/handle/10482/9537. Acesso em: 05 set.2019. 


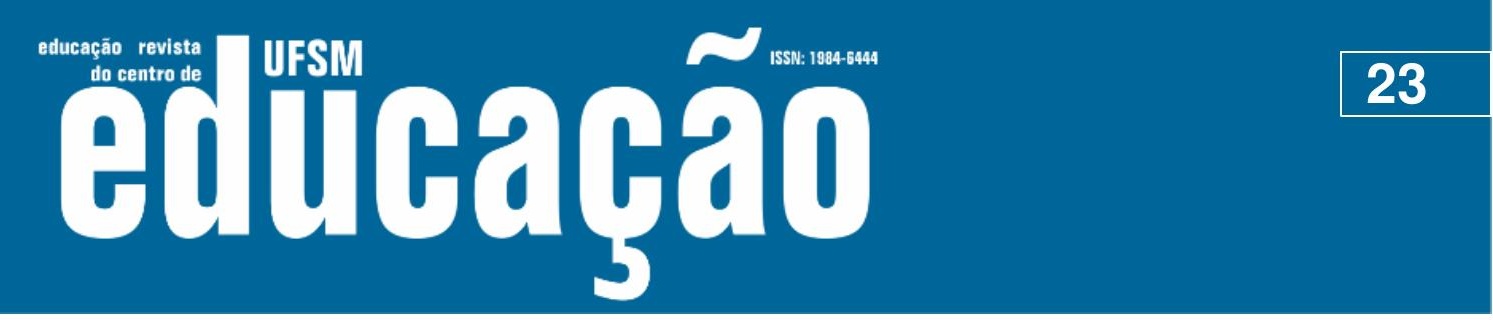

ISSN: 1984-6444 | http://dx.doi.org/10.5902/1984644440682

OLIVEIRA, Rosalina Rodrigues de. Educação integral: cartografia do mal-estar e desafios para a formação docente. [Doutorado em Educação]: Universidade de Brasília, Brasília, 2012. Disponível em: http://repositorio.unb.br/handle/10482/10844. Acesso em: 05 set.2019.

PEREIRA, Marcelo Ricardo, SILVEIRA, Wegis Herculano. Análise do estado da arte em psicanálise e educação no Brasil (1987-2012). Estilos clin., São Paulo, v. 20,n. 3,p. 369-390,dez. 2015. Disponível em:

http://pepsic.bvsalud.org/scielo.php?script=sci_arttext\&pid=S1415-

$71282015000300002 \&$ lng=pt\&nrm=iso.Acesso em: 03 de set de 2019.

PRAZERES, Sandra Mary Gonçalves. Constituição da subjetividade docente: as implicações na prática educativa. [Mestrado em Educação]: Universidade de Brasília, Brasília, 2007. Disponível: http://repositorio.unb.br/handle/10482/2870. Acesso em: 05 set.2019.

SANTOS, David Almeida dos. Afeto e transferência na constituição do sujeito. [Mestrado em Educação]: Universidade de Brasília, Brasília, 2015. Disponível: http://repositorio.unb.br/handle/10482/18816. Acesso em: 05 set. 2019.

SARLO, Beatriz. Tempo Passado: cultura da memória e guinada subjetiva. São Paulo, Companhia das Letras/Belo Horizonte, UFMG, 2007.

SEGUNDA, Katarina Maria Matos de Lacerda. Memorial: uma escrita de si. [Mestrado em Educação]:Universidade de Brasília, Brasília, 2011.Disponível em: http://repositorio.unb.br/handle/10482/8496. Acesso em: 05 set.2019.

SELIGMANN-SILVA, Márcio. A história como trauma. In: NESTROVSKI, Arthur e SELIGMANN-SILVA, Márcio. (Orgs.). Catástrofe e Representação: São Paulo: Editora Escuta,1991. p. 73-98

SILVA NÉTO, Nastassja Lopes. Inconsciente e educação: implicações da psicanálise na formação do pedagogo. [Mestrado em Educação]:Universidade de Brasília, Brasília, 2008.Disponível em: http://repositorio.unb.br/handle/10482/1691. Acesso em: 05 set. 2019.

SILVA, Maria Cecília Pereira da. A escrita como fonte de prazer: relato de uma experiência. J. psicanal., São Paulo, v. 50,n. 92,p. 55-62,jun.2017. Disponível em: http://pepsic.bvsalud.org/scielo.php?script=sci_arttext\&pid=S0103-

$58352017000100004 \&$ lng=pt\&nrm=iso . Acesso em:29 set. 2019.

SQUARISI, Katilen Machado Vicente. O infantil na constituição da subjetividade: o memorial educativo de professores em escrita e ação. [Mestrado em Educação] Universidade de Brasília, Brasília, 2016. Disponível em: http://repositorio.unb.br/handle/10482/22654. Acesso em: 05 set.2019. 
